NOTAS Y DISCUSIONES

\title{
Recuperar a Vitoria
}

\author{
MARTIN C. ORTEGA \\ Universidad de Salamanca
}

Los escrúpulos morales de algunos religiosos, juristas y mandatarios españoles ante la conquista de América durante el siglo Xvi constituyen quizá el caso más llamativo de cuestionamiento ético frente a un problema internacional que ha registrado la historia. Las obras escritas, las discusiones vividas, las leyes promulgadas, así como los acontecimientos políticos a ambos lados del Atlántico, continúan siendo una fuente de inspiración para la reflexión ética sobre las relaciones internacionales. Desde luego, siempre que se acierte a separar el grano de la paja. El esfuerzo que ha hecho la historiografia con el fín de sacudirse la retórica de la epopeya americana ha dado ya sus frutos, $y$ hoy es posible contar con estudios e interpretaciones de gran calidad que nos aproximan a lo que realmente ocurrió. No sucede lo mismo, sin embargo, con la historia de las ideas, pues los pensadores españoles de aquel tiempo siguen enmarañados en las redes de la hagiografía o de la teología, cuando no hundidos en el alegato nacionalista. La obra de Francisco de Vitoria (1483-1546) es un buen ejermplo de esta situación, ya que, salvo refrescantes excepciones, no se encuentran reconsideraciones rigurosas de su pensamiento desde los campos de la filosofía moral, la ciencia política o las relaciones internacionales. Lo cual obliga a realizar un esfúerzo suplementario a la hora de aproximarnos a este autor.

\section{Algunos malentendidos}

Lo primero que conviene advertir es que debe mantenerse a Vitoria en su contexto y no pretender que dijo más de lo que pudo o quiso decir. Esas afirmaciones encendidas de que Vitoria entrevió la Sociedad de Naciones o las Naciones Unidas, o cualquier otro tipo de organización internacional están fuera de lugar. Del mismo modo, Vitoria tampoco fue un precursor de los derechos humanos, idea que, como la concebimos hoy, ni se le pasó por la cabeza. La diatriba sobre si Vitoria es el padre fundador del Derecho internacional moderno (a lo que otros oponen que fue Grocio) debe ser contemplada con el mismo escepticismo. Vitoria era un teólogo que hizo incursiones en problemas prácticos desde un punto de vista cristiano, rechazando con cierto desdén las aproximaciones de los juristas de su tiempo; aunque hizo referencias al ius gentium, su intención no fue elaborar una descripción general de esta materia. Unos detalles que permiten recordar el contexto filosófico en que se movió cl fraile dominico son que, al igual que otros teólogos y humanistas de su tiempo, Vitoria aceptaba la esclavitud en ciertos casos, o también que anduvo muy preocupado por la magia (blanca) y por las condiciones para ejecutar milagros.

Otro malentendido que merece la pena despejar es que existió una «escuela española» del Derecho de gentes con una cierta homogeneidad de planteamientos. El pensamiento de Vitoria se enmarca en una viva 
discusión que tuvo lugar durante la primera mitad del siglo xvi. Desde el mismo descubrimiento, Isabel y Fernando habían albergado ciertas dudas de conciencia sobre el trato a los indígenas, dudas que fueron continuadas por el cardenal Cisneros y aumentadas por el emperador Carlos, que nunca tuvo una política clara hacia América. Estas dudas fueron un reflejo de la misma intelligentsia española, que estuvo dividida sobre la legitimidad de la ocupación de las Indias y sobre el trato que debía darse a sus habitantes. El rico debate fue y sigue siendo inspirador, pero muestra que en España hubo posiciones encontradas sobre estas cuestiones, por lo que dificilmente puede hablarse de una "escuelaw. Tan españoles fueron Palacios Rubios o Juan Ginés de Sepúlveda (que justificaron sutilmente la conquista y la esclavitud natural de los indios) como Vitoria, que mantuvo lo contrario. Del mismo modo, quienes defendieron un mejor trato a las poblaciones indígenas no lo hicieron de una manera uniforme, y así, Vitoria fue recriminado por Las Casas, que mantenía una posición más radical en favor đel indígena. Además, la primera mitad del siglo xvi presenció un debate abierto, de talante renacentista, al tiempo que se leian los clásicos o se recibían en España las influencias de Erasmo, de Lutero y, escandalizados por los excesos de la curia papal, los religiosos españoles abogaban por la imitación de los primeros cristianos. Sin embargo, el Concilio de Trento, el reinado de Felipe II y la contrarreforma provocaron un nuevo tratamiento, menos dubitativo, de la cuestión de América. Ya no se trataba de debatir nada, sino sobre todo de justificar desde el punto de vista político al imperio contra los ataques teóricos del protestantismo y contra el acecho estratégico de las potencias del norte. En este sentido, querer establecer una homogeneidad entre Vitoria y los pensadores de finales del siglo $\mathrm{xvI}$ es demasiado forzado. El contraste entre Vitoria y Suárez, por ejemplo, es muy significativo. Vitoria es un teólogo lleno de dudas, con una gran sensibilidad por los relatos que oye sobre el sufrimiento de los indios; Suárez, en cambio, hace una construcción racionalista y barroca de la teoría del Derecho natural, demasiado apartada de los problemas prácticos que suscitaba el encuentro de sociedades humanas diferentes.

En tercer lugar, una interpretación beatífica de Vitoria lo presenta como un autor coherente, cuyos trabajos encajan a la perfección en una tradición tomista evolucionada. Cuando en realidad lo más interesante de Vitoria son las luchas y tensiones internas que se reflejan en sus escritos. Las contradicciones latentes en su obra lo revelan como un hombre del renacimiento, a pesar de su formación y su fuerte dependencia teológica. Vitoria rechaza las tropelías de sus compatriotas, eque se me hiela la sangre en el cuerpo en mentándomelas» (carta al padre Arcos, 8 noviembre 1534). No obstante, tiene que criticarlas con mesura, ya que «los unos allegan al Papa, y dicen que sois cismático, porque pones duda en lo que el Papa hace, y los otros allegan al Emperador, que condenáis a su Majestad y que condenáis la conquista de las Indias, y hallan quien los oiga y favorezca” (idem). Vitoria debe, por tanto, escribir con el pulso firme para condenar la injusticia sin enemistarse con los poderosos.

\section{Aportaciones de Vitoria}

Teniendo en cuenta esto, no cs de cxtrañar que las importantes contribuciones de Vitoria al juicio ético sobre las relaciones entre los pueblos sean en última instancia un tanto contradictorias. De todas formas, las respuestas pergeñadas por él son tan inteligentes y elegantes que puede considerársele un clásico de la filosofía moral y política, aunque sólo fuera por sus relectiones o conferencias especiales dadas en festividades De temperantia (1537), De Indis y De iure belli (ambas de 1539). Tres enseñanzas de Vitoria pueden destacarse, a las que luego habrá que añadir sus críticas correspondientes.

La aportación quizà más relevante es la consideración de los indios recién descubiertos como hombres racionales, con derechos sobre sus territorios, sus familias y sus cosas. Dios y la naturaleza no han abandonado a 
esos bárbaros en lo indispensable para la especie, y lo principal en el hombre es la razón. Esto es evidente porque tienen cierto orden en sus cosas: disponen de ciudades debidamente regidas, matrimonios bien definidos, magistrados, señores, leyes, industrias y comercio (Vitoria recibió noticias de las civilizaciones azteca e inca). Su cualidad racional les confiere derechos que los espanoles deben respetar. Para valorar esta aportación de Vitoria debe contrastarse con la teoría de la esclavitud natural proveniente de Aristóteles, que fue alegada por diversos filósofos y humanistas para justificar el sometimiento de los indios. La naturaleza racional de los indigenas también da lugar a la elaboración de un nuevo concepto vitoriano, el totus orbis. En la Edad Media se hablaba del orbis christianus en el que el Papa tenía autoridad espiritual y temporal, fuera de cuyos limites estaban los infieles, los paganos y los bárbaros. El profesor de teología de Salamanca, sin basarse aparentemente en ninguna autoridad, establece con gran fuerza la imagen de unos estados cristianos, con autonomía en el campo temporal, que conviven con muchas otras comunidades políticas de diferentes religiones no verdaderas, aunque están compuestas por hombres iguales en su aspecto básico. La Ley divina ilumina sólo a los cristianos, pero las relaciones en este mundo que se acaba de circumnavegar están regidas por un Derecho natural que es común a todos los hombres, y que proviene directamente de su naturaleza racional. El ius gentium serían las disposiciones que regulan las relaciones entre naciones y entre nacionales y extranjeros, que puede provenir del Derecho natural o del «consentimiento de la mayor parte del orbe, sobre todo si está encaminado al bien común». Entre las normas del ius gentium estarian la inviolabilidad de los embajadores, el uso común de los mares, la esclavitud de los prisioneros de guerra o la posibilidad de viajar libremente.

La segunda aportación relevante de Vitoria se halla en el estudio sobre la legitimidad de la apropiación española de las nuevas tierras, a través de una discusión de los títulos juridicos alegados. Niega detalladamente que los siguientes títulos sean legítimos: el emperador es dueño del mundo; el Papa puede conceder la potestad de conquistar; el descubrimiento, que serviria «ni más ni menos para que ellos nos hubieran descubierto a nosotros»; que los bárbaros no quieran recibir la fe de Cristo; que los bárbaros son peca* dores; la elección voluntaria, porque pueden haber intervenido el miedo y la ignorancia; y la existencia una donación especial de Dios, como en el Antiguo Testamento. Sólo hay siete títulos legítimos por los que los bárbaros llegaron a poder de los españoles: el derecho de comunicación natural, que permite a todos los hombres viajar y comerciar con otros; si acaso los indios impidieran la predicación; cuando los bárbaros, al convertirse al cristianismo, quedan bajo la tutela de los espanoles frente a sus principes infieles; si la mayoría de los indios se hacen cristianos porque el Papa puede darles un principe cristiano; para librarlos de la tiranía, sobre todo de las costumbres que atentan contra vidas inocentes; si una «república india» determina por mayoría elegir al rey de España, y finalmente, si un pueblo indio se alía con los españoles contra otro. Además, añade un título que le parece dudoso: que los indios no son idóneos para constituir y administrar una república legítima dentro de límites humanos y políticos.

Los títulos legítimos que Vitoria apunta son muy diferentes entre sí, pero en su construcción, los dos primeros son los únicos realmente importantes. El primer título es una aportación original de Vitoria: el ius communicationis quiere decir que los españoles tienen derecho a tratar pacíficamente con los indios, y éstos no deben impedirlo. El segundo título es, en realidad, un aspecto del primero, ya que en ese intercambio los espanoles pueden predicar la fe cristiana y los indios tienen que permitirlo. En el caso de que se impida la predicación, los españoles tienen derecho a lanzar una guerra justa, pero no en el caso de que los indios no quieran convertirse. Vitoria es consciente al exponer estos títulos de que en la realidad se ha abusado de ambos. Pero lo que importa ahora es apreciar que, dejando aparte los títulos 
de intervención humanitaria y religiosa, y descartados los de origen puramente jurídico, el principal que le queda a Vitoria es en realidad un fundamento de racionalidad, de convivencia pacífica entre los diversos pueblos a través de unas relaciones de diálogo. Es curioso observar que las únicas citas de Ovidio, Terencio y Virgilio en De Indis se contienen en las espontáneas páginas que hablan del ius communicationis. En ellas estamos más cerca de los ensayos de Montaigne que de la Escolástica. Vitoria conoce, por supuesto, la enseñanza de Aristóteles sobre la naturaleza social del hombre, pero en este punto no la utiliza porque parece querer llegar más lejos. La comunicación vitoriana es un principio de ius gentium que incluye el viajar libremente por las tierras y mares de todo el orbe, el comercio, la entrada y establecimiento de extranjeros y, lógicamente, también incluye el deber de los príncipes de respetar estos derechos.

En la enumeración de los títulos Vitoria muestra gran coraje a la hora de separarse de las doctrinas imperialistas. EI emperador no es señor del orbe porque los hombres son libres por Derecho Natural, y establecen diversas comunidades políticas. Evidentemente, tanto estas declaraciones como una discusión tan original de los títulos, que abría la posibilidad de sucesivas críticas, sólo podía favorecer a los enemigos del emperador. Igualmente, es valiente la oposición a la autoridad que el Papado pretendía ejercer como continuación de la Edad Media. Las órdenes religiosas lucharon intentando reformar la Iglesia viciada y reclamando directamente a la corona actuaciones justas. Vitoria niega que el Papa tuviera poder para entregar a través de las Bulas las tierras del nuevo mundo a los españoles o a ningún otro. Con estas afirmaciones se convierte en uno de los primeros teóricos de la sociedad moderna de Estados independientes.

En relación con el cuarto título no legítimo y con el segundo legítimo, surge la última aportación de Vitoria que vamos a comentar: la libertad de los infieles para convertirse. En la Iglesia medieval predominaba la doctrina de las guerras de religion, que justificaba las cruzadas a tierra santa, y esta doctrina también se aplicó en los primeros momentos a la conquista de América. Cuando todavía se vivía la resaca de la cuarta cruzada, santo Tomás de Aquino diferenció entre los herejes, que habían tenido oportunidad de conocer la fe de Cristo pero la negaban o la tergiversaban, y lus que no habían tenido posibilidad de escuchar la palabra de Dios. La ignorancia era la clave que diferenciaba el tratamiento de los herejes y los gentiles. Vitoria subrayó que estos últimos, por ser hombres racionales, tenían la libertad de recibir la palabra de Dios. Esta visión está libre de muchos de los prejuicios religiosos de la época. Hay que tener en cuenta que en ese mismo momento el gran enemigo de los Habsburgo es el imperio turoo que, avanzando rápidamente por el Danubio, había llegado a sitiar Viena en 1529. Carlos $V$ dirige personalmente las campañas contra las costas de Argelia y Túnez de 1530 a 1535 . Las guerras justas que se desarrollaban contra los musulmanes eran encarnizadas y daban derecho a adquirir esclavos. Algunos comentaristas de la época (y desde luego los conquistadores) se cegaron por estas guerras y por el precedente de la reconquista en España, y consideraban a los nuevos indios tan infieles como los moros. Vitoria defiende ampliamente que los indios no han de ser obligados a recibir la fe cristiana, ni con la guerra ni con amenazas y tormentos. Los musulmanes españoles convertidos rápidamente no lo habían hecho con sinceridad, por lo que de esa forma no se hacía un buen servicio a la causa de la cristiandad. Tampoco debe emplearse la fuerza contra los indios por sus pecados. Con independencia de la ley divina, que no conocen, los indios están obligados por el Derecho Natural a no realizar actos odiosos; pero aquí Vitoria distingue entre los preceptos que pueden incumplir bajo su responsabilidad, como la fornicación o la usura, y las violaciones que requieren intervención externa, como la sodomía o el canibalismo. La distinción está basada en el respeto a la vida de los demás. Cuando un inocente es conducido al sacrificio, los españoles están obligados a salvarlo aunque no pida ayuda o no lo quiera, «como 
puede obligarse a un enfermo a tomar la medicina». El método de la propagación đe la palabra es la convicción, la fuerza de la razón, acompañada por el testimonio de una vida digna y diligente $\mathrm{y}$, si es posible, por la realización de milagros. Dios ha puesto la razón natural a todos los hombres y no les obliga a creer lo que no comprenden. Por lo que los indios no están obligados a creer en Cristo en el primer anuncio, ya que si se les hubiera predicado la religión musulmana no hubieran tenido modo de saber si era más verdadera que el cristianismo.

\section{Crítica}

Trcs reproches pueden dirigirse a Vitoria, paralelos a las tres aportaciones descritas. El teólogo de Salamanca rompe con ciertos prejuicios medievales ayudado de la razón, del Nuevo Testamento y de santo Tomás, pero no puede llegar a las últimas conclusiones, y él mismo parece darse cuenta de ello. Por este motivo se observan ciertas incoherencias en su obra, que los estudiosos vitorianos no destacan lo suficiente.

Aunque Vitoria acepta que las sociedades indias tienen un cierto orden representado por sus príncipes, magistrados y señores, incluso religion, no llega a reconocerles ningún estatus internacional como comunidad política. Cuando discute la posibilidad de una asociación voluntaria con la corona española, en el sexto título, considera la forma de adoptar decisiones por comunidades que llama abiertamente «repúblicas» asi como las relaciones entre el «pueblo» y el «príncipe». Sin embargo, en otros momentos duda de la capacidad de los indios para mantener un gobierno propio (como en el alegado octavo título). Esta contradicción proviene de una cierta (y quizá inevitable) complacencia con la nueva gobemación establecida. Por ello, tiene que imaginar una república indiana cuyo soberano es el rey de España, como otros territorios que hay llegados a su poder por otros títulus. El rey debe actuar correctamente frente a sus nuevos súbditos $y$, además de suprimir las costumbres bárbaras y predicar la fe cristiana, debe conservar y aumentar sus bienes materiales. Vitoria deja asi la cuestion de la convivencia entre indios y cristianos en esas repúblicas indias al cuidado del rey, sobre cuya conciencia descarga la responsabilidad del buen trato a los indios.

El ius communicationis también tiene una definición dificil en la obra de Vitoria en un punto. Al parecer el derecho existe, según el ius gentium, tanto entre europeos como en la relación con el Nuevo Mundo, y todos los hombres deberían poder ejercitarlo. Ahora bien, Vitoria incluye en este derecho la posibilidad de aprovechar las res nullius y las res communis que se encuentran en los mares, en los ríos y en la tierra; sin embargo, no define en ningún momento estas cosas con relación a la propiedad reconocida a los indígenas. Vitoria habla del oro que se encuentra en las Indias en diversas ocasiones y de otras riquezas, y parece que los considera res nullius, que los españoles pueden aprovechar en virtud del ius communicationis. Pero cuando menciona ejemplos de este mismo derecho entre españoles y franceses no parece aplicable con la misma extensión. Es significativo cómo Vitoria utiliza en muchas ocasiones el razonamiento analogico para subrayar la igualdad de los indios. Dice que ellos son hombres racionales a imagen de Dios, que también podrían habernos querido conquistar, que guerrear con ellos es como atacar la ciudad de Sevilla, y que su atraso es comparable al de los rústicos de España. No obstante, cuando se refiere a la realización efectiva de los derechos de propiedad que ha reconocido se quiebra el carácter reflexivo.

En la obra de Vitoria se intentan precisar las causas para legitimar la guerra contra los indios y se rechaza la doctrina de la guerra justa de religión. Es evidente que en aquel ambiente fue una sensibilidad especial la que llevó a reconocer cierta libertad a los indígenas para convertirse o no. Ahora bien, el fin último que perseguía Vitoria le traicionó. Vitoria apunta que los indios originarios podrían salvarse cumpliendo la ley natural y viviendo honestamente, y solo podían condenarse por otros pecados graves, pero no por la infidelidad. Una vez conocida la pala- 
bra de Dios, es la razón y la voluntad, y no la fuerza, lo que les hará convertirse. Sin embargo, la creencia rotunda en la supremacía religiosa y cultural de los cristianos deja sin contenido la decisión del índio. Mostrando un gran idealismo, Vitoria no prevé la posibilidad de que, tras la indoctrinación, no se abrace la fe. En su estudio de Salamanca, Vitoria imaginaba una conversación socrática, como sus discusiones académicas, que estaba muy lejos de la realidad.

\section{Las concepciones universalista y estatista de las relaciones internacionales}

A pesar de las críticas, la obra de Vitoria emerge como una anticipación de la igualdad de todos los hombres, cualquiera que sea su condición, y de la convivencia pacífica de las diversas naciones en un totus orbis. Su obra ejerció una gran influencia en su Universidad, que produjo una serie de teólogos ilustres hasta entrado el siglo xvir y que llevó a cabo una labor docente con gran repercusión en América. La discusión sobre el indio en España se proyecta en el derecho que va a implantarse, aunque estableció un estatus superior para el colonizador.

No obstante, de forma paulatina, las enseñanzas críticas del maestro, con una gran dimensión práctica, van siendo transformadas por sus discípulos en teorías alejadas de la realidad. El desarrollo posterior de la teoría del Derecho Natural le hace perder la frescura con que Vitoria lo aplicó. Al mismo tiempo en Europa pronto empiezan a desvanecerse los ecos de su doctrina. La influencia de Vitoria parece una agradable brisa de verano que va debilitándose para dar paso a los vientos tormentosos de la guerra en Europa. La obra de Vitoria es injustamente olvidada por los filosofos y pensadores políticos europeos.

Las preocupaciones de Vitoria están penetradas de las tensiones típicas del renacimiento. Los religiosos españoles, que reciben fuertes influencias humanistas y que conocen a los clásicos, se encontraron con una cues- tión internacional de inmensas propotciones. El principio del que parten, expuesto magistralmente por Vitoria, es que la actuación española en las Indias no es sólo un problema legal que puedan resolver los juristas, sino que es una cuestión que afecta a las conciencias; en nuestro lenguaje, una cuestión ética. Para resolver cuestión tan importante echaron mano de los instrumentos que terian a su alcance. La obra de santo Tomás es una fuente de inspiración constante para Vitoria. Pero el profesor de Satamanca no es un escolástico puro, sencillamente porque las circunstancias no permiten especulaciones deductivas. No hay más remedio que utilizar la razón práctica. En el comienzo de la Summa contra gentiles santo Tomás había avisado que en las discusiones con mahometanos y paganos no es posible argüir las verdades de la Sagrada Escritura porque no las admiten. Por ello, debe recurrirse a la razón natural, que todos se ven obligados a aceptar. En $D e$ Indis Vitoria pone en funcionamiento esta idea no sólo para convertir a los indios a su civilización y su fe, sino para convencer a sus compatriotas, que él sabe que muchas veces no se ven conmovidos por las argumentaciones teológicas.

Pero la razón es el método de Vitoria, que tiene un motor y un fin. La misma indignación profunda que embarga a los predicadores recién llegados a las Indias, la condena de la injusticia palpable, es la raíz de toda la obra vitoriana. La verdadera fuente que mueve su discurso es una sensibilidad humana de origen cristiano, pero para llamarlo como él lo habría hecho, su fuente es la caridad, que había estudiado detalladamente como amor al prójimo. Para fundamentar afirmaciones comprometidas echa mano directamente del Evangelio, pero tambiên tiene que conjugar esa philosophia Chris$t i$ con la realidad. Vitoria comprende que su reino está involucrado sin remedio en la conquista de vastas tierras, y cree necesario extender la fe y la civilización a los indios. Su manera particular de introducir la ética en las relaciones internacionales fue poner directamente en la conciencia del rey la necesidad del trato más respetuoso posible a los 
indios. Quizá en ese momento poco más podía hacerse.

La genial aportación de Vitoria al pensamiento sobre las relaciones entre los pueblos es la advertencia de que el mundo entero está habitado por personas iguales en lo esencial: su naturalcza racional, que les atribuye derechos, propiedades y voluntad libre. El Derecho Natural, que proviene de la común naturaleza de los hombres, contiene las normas que se aplican a todos ellos, y en especial les permite relacionarse libremente y comerciar con todos los demás. Vitoria no conocía seguramente a los estoicos clásicos, sino que se inspira en el Nuevo Testamento y en la síntesis de Aquino para regenerar una concepción universalista. $Y$ aqui podemos decir que surge un significado de la teoría de Vitoria que tampoco ha recibido mucha atención, porque en realidad no se encuentran estudios comparativos de su pensamiento. En el Renacimiento tienen origen dos concepciones de las relaciones internacionales, la estatista, representada por Maquiavelo, y la universalista, por Vitoria. El florentino escribe sobre todo entre 1513 y 1520 con dos propósitos: obtener un cargo público importante de los Medici y hacer que su Estado gane prestigio y poder. Maquiavelo mira al bien de una única república cuyo príncipe debe esforzarse por todos los medios para conseguirlo frente a otros Estados. Como admirador de los romanos, las relaciones con el mundo exterior de los Estados cristianos están presididas por ta idea del establecimiento de colonias. Las colonias, según él, son batatas, y los perjudicados no pueden causar problemas si son pocos o se les ha aplastado, porque quedan pobres $\mathrm{e}$ indefensos, y las ofensas ligeras se vengan pero las graves no pueden serlo. Los autores del Renacimiento que constituyen el humanismo cristiano, como Erasmo o Vives, propugnan la actuación correcta de los príncipes y defienden un pacifismo idealista, pero no sienten cercanos los problemas de América, por lo que tampoco tienen la conciencia universal que despliega Vitoria. El simbolo más gráfico de la actitud estatista es la destrucción del istmo que une a Utopía con el continente. Tomás Moro habla de la tole- rancia religiosa y otras costumbres dentra de aquel Estado, pero muestra un cierto desprecio por las relaciones con los otros pueblos.

Sin duda, el auge del estatismo tiene que ver con el antropocentrismo que la época moderna inauguró. Sin embargo, el optimismo con el que el Renacimiento mira las facultades del bombre dará paso pronto a la constatación palpable de su crueldad y cortedad de miras, como va a exponer enérgicamente Hobbes y van a poner de manifiesto con amargura Shakespeare y Cervantes. Antes de ellos, Montaigne recomendó combatir la «inhumanidad» del hombre con la contención; con la simple adecuación a sus propias posibilidades. Vitoria es testigo directo de una de las causas de frustración que van a sentir estos grandes hombres de un nuevo periodo, y tuvo la posibilidad de influenciar al personaje más poderoso de su mundo. Desde esta perspectiva, la obra de Vitoria aparece como un modelo de equilibrio, pero también de impotencia.

Es evidente que la dimensión ética de las relaciones entre los Estados y otros sujetos no se ha desarrollado mucho a lo largo de la Edad Moderna. Asimismo, la tradición estatista ha dominado totalmente las relaciones internacionales hasta la creación de las Naciones Unidas. He aquí dos ideas truncad́as, que quizá no constituyen dos, sino un solo vínculo olvidado. La teoría de las relaciones internacionales está ahora ocupándose ampliamente de este vínculo; pero da la impresión de que la formulación original de la disyuntiva entre estatismo y universalismo que se contiene en los escritos de esas dos figuras tan dispares del siglo xvi como son Maquiavelo y Vitoria no ha sido superada.

\section{BIBLIOGRAFIA RECIENTE}

Castilla Urbano, Francisco (1992): El pensamiento de Francisco de Vitoria, Anthropos, Barcelona.

Fernández Santamaría, J. A. (1988): El Estado, la guerra y la paz. El pensamiento 
politico español en el renacimiento [1977] Madrid, Akal.

Grt, Juan (1990): «Conquista y justicia: Espania $y$ las Indias», en Fernando Vallespin (ed.), Historia de la teoría politica, vol. 2, Madrid, Alianza.

Hernandez Martin, Ramón (1995): Francisco de Vitoria. Vida y pensamiento intemacionalista, Madrid, Biblioteca de Autores Cristianos.

ORTEGA, Martín (1996): «Vitoria and the universalist conception of internacional relations», en I. CIARK \& I. NeumanN (eds.), Classical theories of intemational relations, Londres, Macmillan.
Padgen, Anthony, \& Lawrance, Jeremy (1991): Francisco de Vitoria. Political writings, Cambridge, Cambridge University Press.

Pérez Luño, Antonio Enrique (1992): La polémica sobre el Nuevo Mundo, Madrid, Trotta.

Ramos, Demetrio, et al. (1984): La écica en la conquista de América, Madrid, CSIC. Subirats, Eduardo (1994): El continente vacio. La conquista del Nuevo Mundo y la conciencia moderna, Madrid, Anaya-Mario Muchnik.

Trros Lomas, Francisco (1993): La filosofia politica y jurídica de Francisco de Vitoria, Córdoba, Caja de Ahorros de Córdoba. 